\title{
Cord Plasma Vasopressin, Erythropoietin, and Hypoxanthine as Indices of Asphyxia at Birth
}

\author{
VINETA RUTH, FREJ FYHRQUIST, GISELA CLEMONS, AND KARI O. RAIVIO
}

Children's Hospital [V.R., K.O.R.] and IVth Department of Medicine [F.F.], University of Helsinki, Helsinki, Finland; and Lawrence Berkeley Laboratory [G.C.], University of California, Berkeley, California

\begin{abstract}
To assess the value of cord plasma arginine vasopressin (AVP), erythropoietin (EP), and hypoxanthine (HX) as indices of asphyxia, we studied 62 infants of mothers with preeclampsia, 34 acutely asphyxiated infants, with 5-min Apgar score $\leq 6$ and/or umbilical arterial $\mathrm{pH}$ $\leq 7.05$, and 38 control infants. Umbilical arterial AVP in the asphyxia group (geometric mean; $95 \%$ confidence interval: $180 ; 92-350 \mathrm{pg} / \mathrm{ml}$ ) was higher than in the control group $(23 ; 8-66, p=0.002)$ and correlated with umbilical arterial pH $(r=-0.447, p=0.028)$. AVP levels in the preeclampsia group did not differ from controls. Cord venous $\mathrm{EP}$ was higher in infants delivered by elective cesarean section from women with severe preeclampsia $(115 ; 75-177 \mathrm{mU} / \mathrm{ml}, p<0.001)$ than in control infants (23; 18-27); in the whole group EP correlated with $\mathrm{pH}(r$ $=-0.493, p<0.001)$. EP in the asphyxia group was similar $(46 ; 35-65)$ to controls $(40 ; 33-47)$ and did not correlate with $\mathrm{pH}$. Cord arterial $\mathrm{HX}$ in the preeclampsia group was similar to controls $(12.3 ; 9.5-16.0 \mu \mathrm{mol} / \mathrm{liter})$, but elevated in the asphyxia group $(23.7 ; 17.6-31.8, p=$ $0.001)$, in which $\mathrm{HX}$ correlated with $\mathrm{pH}(r=0.558, p=$ $0.008)$ and AVP $(r=0.588, p=0.005)$. EP did not correlate with AVP or $\mathrm{HX}$ in any group, nor did any of the variables correlate with the Apgar score. We conclude that cord plasma AVP and $H X$ reflect acute asphyxia, whereas EP is elevated after more prolonged hypoxia. (Pediatr Res 24: 490-494, 1988)
\end{abstract}

Abbreviations

AVP, arginine vasopressin

EP, erythropoietin

HX, hypoxanthine

Birth asphyxia is usually defined and its severity graded on the basis of the Apgar score. Although useful for evaluating the need for and the response to resuscitation, the Apgar score is at best an indirect indicator of the effects of hypoxia, hypercarbia, and circulatory disturbance on the fetus and newborn (1). Maternal analgesia or anesthesia and prematurity are associated with low scores in the absence of asphyxia, and poor correlation has been found between the Apgar score and the $\mathrm{pH}$ in umbilical arterial blood (2). Furthermore, the predictive value of the Apgar score with respect to perinatal brain damage is limited (3).

Received March 28, 1988; accepted June 14, 1988.

Correspondence and reprints Vineta Ruth M.D. Children's Hospital, Stenbäckinkatu 11, 00290 Helsinki, Finland.

Supported by grants from The Foundation for Pediatric Research, Signe and Ane Gyllenberg Foundation, the Sigrid Juselius Foundation, and The Paulo Foundation
Fetal asphyxia and delivery trigger a rapid increase in the secretion of several "stress" hormones, e.g. catecholamines, glucocorticoids, ACTH, $\beta$-endorphin, and AVP, which in turn mediate the cardiovascular and metabolic adaptation to asphyxia (4-6). A more specific response to hypoxia is an increase in the synthesis of EP, followed by elevation of plasma levels $(7,8)$. If tissue hypoxia becomes more severe, cellular ATP concentrations cannot be maintained, and increased concentrations of the purine nucleotide catabolic products, $\mathrm{HX}$, xanthine, and uric acid, appear in body fluids (9).

The aim of our study was to assess if three components of this physiological response, AVP, EP, and HX, could be useful as biochemic indices of the severity of asphyxia. Two different clinical conditions were studied: acute severe birth asphyxia and maternal preeclampsia, the latter as an example of a chronic but less severe compromise in fetal oxygen and nutrient supply.

\section{MATERIALS AND METHODS}

Subjects. All the infants were born at the Women's Hospital, University of Helsinki. The study protocol was approved by the ethical committees of the Women's and Children's Hospitals, University of Helsinki. Informed consent was obtained from both parents, if possible.

The preeclampsia group consisted of 62 infants, including two pairs of twins (Table 1). The selection criteria were maternal blood pressure in the third trimester either more than $140 / 90$ $\mathrm{mm} \mathrm{Hg}$ with proteinuria in excess of $1 \mathrm{~g} /$ day, or more than 160/ $110 \mathrm{~mm} \mathrm{Hg}$ without proteinuria but with intrauterine growth retardation. All mothers were hospitalized for antenatal monitoring with repeated cardiotocography (nonstress tests) and amniocenteses for determination of lung maturity (10). Nine mothers were treated with hydralazine, four with a $\beta$-blocking agent, 27 with a combination of the two, six with a combination of either or both with clonidine, whereas 14 had no antihypertensive medication. Elective cesarean section (i.e. without labor) was performed because of severity of preeclampsia in 44 mothers. Labor was induced in 13 cases, whereas three had spontaneous labor.

The acute asphyxia group (Table 1) consisted of 34 infants, born after uneventful pregnancy and spontaneous labor, but the deliveries were complicated by severe asphyxia, defined as an Apgar score of 6 or less at $5 \mathrm{~min}$ and/or an umbilical arterial pH of 7.05 or less. Fetal distress necessitated instrumented delivery in 18 cases, 11 by cesarean section, six with vacuum extraction, and one with forceps. One infant had Erb's palsy and three had fracture of the clavicle.

The control group (Table 1) consisted of 38 infants fulfilling the following criteria: 1 ) maternal age 18 to $35 \mathrm{yr}, 2$ ) previously healthy mother, 3) no complication or medication during pregnancy, 4) singleton pregnancy, 5) gestational age 38 to $41.3 \mathrm{wk}$, 6) uneventful vaginal delivery, 7) birth weight appropriate for gestational age (within \pm 1.5 SD from the mean of a singleton 
Table 1. Neonatal clinical characteristics of study subjects

\begin{tabular}{|c|c|c|c|}
\hline & $\begin{array}{c}\text { Preeclampsia } \\
\text { group }(n=62)\end{array}$ & $\begin{array}{c}\text { Asphyxia } \\
\text { group }(n=34)\end{array}$ & $\begin{array}{c}\text { Control } \\
\text { group }(n=38)\end{array}$ \\
\hline \multicolumn{4}{|l|}{ Maternal characteristics } \\
\hline Age (yr) & $30.2 \pm 1.9$ & $28.8 \pm 4.7$ & $29.1 \pm 3.9$ \\
\hline Smoking & 8 & 8 & 7 \\
\hline \multicolumn{4}{|l|}{ Mode of delivery } \\
\hline Vaginal & 8 & 23 & 38 \\
\hline Elective cesarean section & 46 & 0 & 0 \\
\hline Emergency cesarean section & 8 & 11 & 0 \\
\hline \multicolumn{4}{|l|}{ Delivery complication } \\
\hline Meconium stained fluid & 1 & 11 & 0 \\
\hline Abruption of placenta & 1 & 2 & 0 \\
\hline Gestational age (wk) & $35.1 \pm 2.4^{*}$ & $38.6 \pm 3.8 \dagger$ & $40.3 \pm 0.9$ \\
\hline Birth wt (g) & $2030 \pm 720 \ddagger$ & $3190 \pm 980$ & $3465 \pm 260$ \\
\hline Small for gestational age (less than $-2 \mathrm{SD}$ ) & 29 & 5 & 0 \\
\hline Male/female & $28 / 34$ & $16 / 18$ & $25 / 13$ \\
\hline \multicolumn{4}{|l|}{ Umbilical arterial } \\
\hline $\mathrm{pH}$ & $7.26 \pm 0.06 \ddagger$ & $7.08 \pm 0.11^{*}$ & $7.30 \pm 0.06$ \\
\hline Lactate (mmol/liter) & $3.2 \pm 1.9$ & $6.1 \pm 3.4^{*}$ & $2.8 \pm 0.9$ \\
\hline \multicolumn{4}{|l|}{ Apgar score $<7$} \\
\hline $1 \mathrm{~min}$ & 5 & 21 & 0 \\
\hline $5 \mathrm{~min}$ & 3 & 17 & 0 \\
\hline Intubated at birth & 7 & 18 & 0 \\
\hline Mechanically ventilated $>12 \mathrm{~h}$ & 4 & 13 & 0 \\
\hline \multicolumn{4}{|l|}{ Neonatal diagnoses } \\
\hline Meconium aspiration syndrome & 0 & 7 & 0 \\
\hline Respiratory distress syndrome & 5 & 1 & 0 \\
\hline \multicolumn{4}{|l|}{ Hypoxic-ischemic encephalopathy } \\
\hline Mild & 1 & 3 & 0 \\
\hline Moderate & 0 & 4 & 0 \\
\hline Severe & 0 & 3 & 0 \\
\hline Death: neonatal/later & $1 / 1$ & $1 / 0$ & $0 / 0$ \\
\hline
\end{tabular}

Parametric data are expressed as mean $\pm \mathrm{SD}$, and their significance compared to controls as follows: ${ }^{*} p<0.001 ; \dagger p<0.05 ; \ddagger p<0.01$.

birth population of 75,000 infants in the Helsinki region in 1978-1982), 8) umbilical arterial $\mathrm{pH}$ of 7.18 or more and base deficit less than $15 \mathrm{mmol} / \mathrm{liter}$, 9) Apgar score 8 or more at 1 and $5 \mathrm{~min}$, and 10 ) no neonatal complications.

Because the mode of delivery may influence the measured parameters, and our control group infants all were delivered vaginally, separate reference values were obtained from infants delivered by elective cesarean section without labor (contracted pelvis, repeat section) otherwise fulfilling the control group criteria. The reference values for $\mathrm{HX}$ were obtained from nine infants, for AVP and EP from previously published data, which had been analyzed in the same laboratories as for the present study $(11,10)$.

Except for umbilical blood sampling at birth, routine clinical procedures were followed in the management of the deliveries, including fetal heart rate monitoring and scalp capillary blood $\mathrm{pH}$ measurements, when indicated. The Apgar score was assigned at 1 and $5 \mathrm{~min}$ by the midwife or pediatrician responsible for the newborn infant.

Blood sampling and analyses. The umbilical cord was doubly clamped before the first cry and the cord segment placed in an ice bath. Blood was immediately drawn into heparinized syringes separately from an artery and vein. An aliquot of arterial blood was precipitated with perchloric acid and stored at $-20^{\circ} \mathrm{C}$ until enzymatic lactate determination (Boehringer/Mannheim Biochemicals, Indianapolis, IN Kit no. 149993). Centrifugation of arterial and venous blood at $+5^{\circ} \mathrm{C}$ and blood gas determination (Corning pH/Blood Gas Automatic Analyzer model 178, Corning Medical, Medfield, MA) from arterial blood were performed without a median time of $10 \mathrm{~min}$ after birth. Plasma samples were stored at $-20^{\circ} \mathrm{C}$ until analyses. $\mathrm{HX}$ was measured in umbilical arterial plasma, after deproteinization with methanol, using a Waters high-performance liquid chromatography system with a $\mu$ Bondapak C 18 reverse-phase column (12). To ascertain the quantification of the $\mathrm{HX}$ peak, the assay was repeated after incubation of the sample with xanthine oxidase. The coefficient of variation was $4 \%$. AVP was determined from umbilical arterial plasma by radioimmunoassay (13). Cross-reaction of the AVP antiserum with oxytocin (Sandoz, Basel, Switzerland) was $0.3 \%$, with pressinoic acid (Ferring, Malmö, Sweden) $0.1 \%$, and with C-terminal tripeptide of AVP (Ferring) $0.2 \%$. The detection limit was $0.2 \mathrm{pg} / \mathrm{ml}$, corresponding to $1.2 \mathrm{pg} / \mathrm{ml}$ of plasma. The intraassay coefficient of variation was $10.5 \%$ in the low range and $11.6 \%$ in the high range. EP in venous plasma was measured with a double-antibody radioimmunoassay (14). Linear values are obtained between 5 and $100 \mathrm{mU} / \mathrm{ml}$, appropriate dilutions were made for those samples with higher concentrations. The interassay coefficient of variation was between 9 and $13 \%$. Because of small blood volumes in the clamped cord segments, all parameters could not be measured in all infants.

Data analysis. Reference values were derived from the control infants, and the upper limit of normal was defined as the 97th percentile. Based on a study of 982 consecutive deliveries (15), we defined an umbilical arterial $\mathrm{pH}$ less than 7.16 and a lactate concentration more than $5.4 \mathrm{mmol} /$ liter as abnormal after vaginal delivery, whereas after elective cesarean section the respective values were 7.25 and $3.3 \mathrm{mmol} / \mathrm{liter}$.

Data analyses were performed using the BMDP statistical software. Natural logarithmic transformation was used to normalize the skewed distribution of AVP, EP, and HX concentrations. Analysis of variance, Student's $t$ test, Mann-Whitney test, and the $\chi^{2}$ test were used for comparisons between groups, as appropriate. Linear regression was used for analyzing the relationships between the hypoxia parameters studied. Discriminant analysis was used for assessing if a combination of hypoxia parameters could predict neonatal morbidity related to asphyxia. 


\section{RESULTS}

Apgar score and $p H$. Because of the selection criteria for the present study, all infants in the acute asphyxia group, but none in the control group, had an abnormal Apgar score and/or umbilical arterial $\mathrm{pH}$. In the preeclampsia group, three infants had an Apgar score of 7 or less at 5 min and 14 had an abnormally low umbilical arterial $\mathrm{pH}$, but none had a $\mathrm{pH}$ less than 7.05. By linear regression analysis, there was a negative correlation between the 5-min Apgar score and the umbilical arterial $\mathrm{pH}$ in the asphyxia group $(r=-0.364, p=0.034, n=34)$, but not in the preeclampsia and control group separately.

Umbilical arterial lactate concentration was measured in 31 infants in the preeclampsia, in 29 in the asphyxia group, and in all control infants (Table 1). Values exceeded the upper limit of normal in eight infants in the former and 14 in the latter group. The levels were not correlated with the Apgar score.

Vasopressin. In the preeclampsia group, infants born after labor had higher AVP concentrations than those born after elective cesarean section, but the difference in comparison to control infants with same mode of delivery was not significant (Table 2). Thirteen infants had values higher than the upper limit of normal. AVP concentrations were not correlated with umbilical arterial $\mathrm{pH}$ or lactate or with the Apgar score.

In the acutely asphyxiated infants, umbilical arterial AVP concentrations were significantly $(p=0.002)$ higher than in the control group, both groups of infants being born after labor (Table 2). Only three infants had levels higher than the upper limit of normal. The AVP concentrations were correlated with umbilical arterial $\mathrm{pH}(r=-0.447, p=0.028$, Fig. 1), but not with lactate $(r=0.381, p=0.08, n=22)$ or the Apgar score $(r$ $=0.234, p=0.274, n=24)$. The presence of meconium was not related to the AVP levels.

Erythropoietin. In the preeclampsia group, the infants delivered by elective cesarean section had higher levels of EP than those born after labor. They were even significantly higher than in the vaginally delivered control group (Table 2). In 34 infants the concentration exceeded the upper limit of normal. EP was significantly correlated with umbilical arterial pH $(r=-0.493$,

Table 2. Plasma concentrations of $A V P, E P$, and $H X$ in cord blood

\begin{tabular}{|c|c|c|c|}
\hline & & $\begin{array}{c}\text { Geometric } \\
\text { mean }\end{array}$ & $\begin{array}{l}95 \% \text { confidence } \\
\text { limits of } \\
\text { the mean }\end{array}$ \\
\hline \multicolumn{4}{|l|}{$\operatorname{AVP}(p g / m l)$} \\
\hline \multirow[t]{2}{*}{ Preeclampsia } & labor $(n=13)$ & 92 & $22-390$ \\
\hline & no labor $(n=30)$ & 14 & $6-30$ \\
\hline Acute asphyxia & labor $(n=24)$ & $180^{*}$ & $92-350$ \\
\hline \multirow[t]{2}{*}{ Control } & labor $(n=30)$ & 23 & $8-66$ \\
\hline & no labor $(n=8) \ddagger$ & 13 & $9-18$ \\
\hline \multicolumn{4}{|l|}{$\mathrm{EP}(\mathrm{mU} / \mathrm{ml})$} \\
\hline \multirow[t]{2}{*}{ Preeclampsia } & labor $(n=16)$ & 67 & $38-119$ \\
\hline & no labor $(n=46)$ & $115 \dagger$ & $75-177$ \\
\hline Acute asphyxia & labor $(n=31)$ & 46 & $35-65$ \\
\hline \multirow[t]{2}{*}{ Control } & labor $(n=37)$ & 40 & $33-47$ \\
\hline & no labor $(n=17) \S$ & 23 & $18-27$ \\
\hline \multicolumn{4}{|l|}{$\mathrm{HX}(\mu \mathrm{mol} /$ liter $)$} \\
\hline \multirow[t]{2}{*}{ Preeclampsia } & labor $(n=14)$ & 13.1 & $9.8-17.4$ \\
\hline & no labor $(n=40)$ & 9.1 & $7.8-10.5$ \\
\hline Acute asphyxia & labor $(n=24)$ & $23.7^{*}$ & $17.6-31.8$ \\
\hline \multirow[t]{2}{*}{ Control } & labor $(n=36)$ & 12.3 & $9.5-16.0$ \\
\hline & no labor $(n=9)$ & 12.5 & $9.0-17.5$ \\
\hline
\end{tabular}

Difference in comparison to control group with the same mode of delivery $* p<0.01 ; \dagger p<0.001$.

$\ddagger$ Reference 11 .

$\S$ Reference 10. $p<0.001$, Fig. 2) and lactate $(r=0.518, p=0.002, n=31)$, but not with the Apgar score or gestational age. However, there was a positive correlation with the degree of intrauterine growth retardation, as shown by the significant negative correlation with the SD score $(r=-0.305, p=0.016)$. EP did not correlate with cord arterial AVP concentration in the preeclampsia group.

The mean EP concentration in the acute asphyxia group was similar to that in the control group. Seven infants had values higher than the upper limit of normal. There was no correlation with the Apgar score, umbilical arterial $\mathrm{pH}$ or lactate, or cord arterial AVP concentration.

Hypoxanthine. In the preeclampsia group, regardless of mode of delivery, cord arterial HX concentrations were in the reference range. They were not correlated with $\mathrm{pH}$, lactate, the Apgar score, gestational age, AVP, or EP.

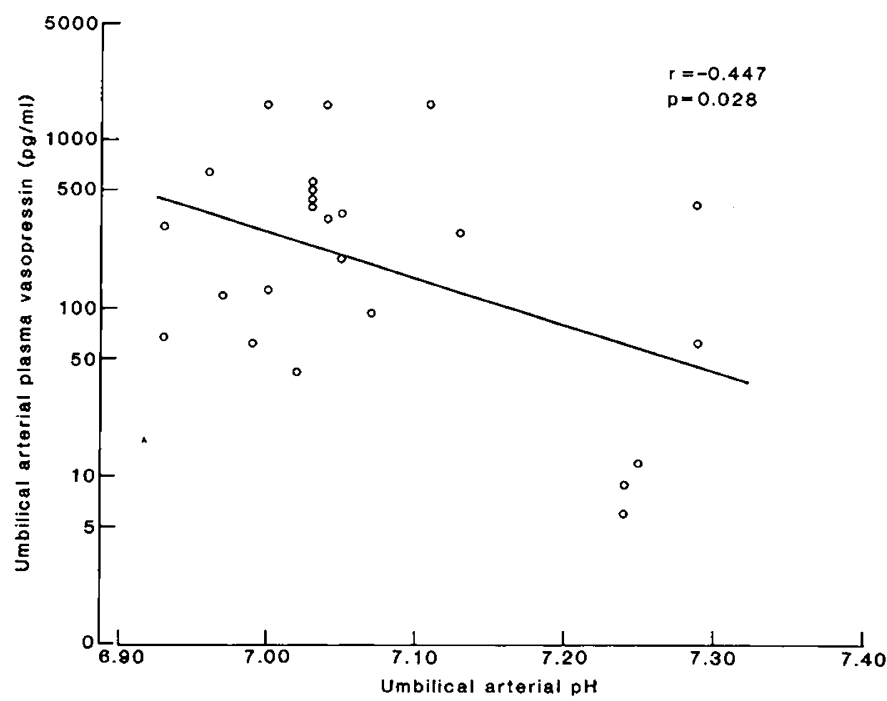

Fig. 1. Correlation between logarithmically transformed plasma vasopressin concentration and $\mathrm{pH}$ in umbilical artery of acutely asphyxiated infants $(n=24)$. The regression line $(\mathrm{Y}=50-6.34 \times \mathrm{X})$ is shown.

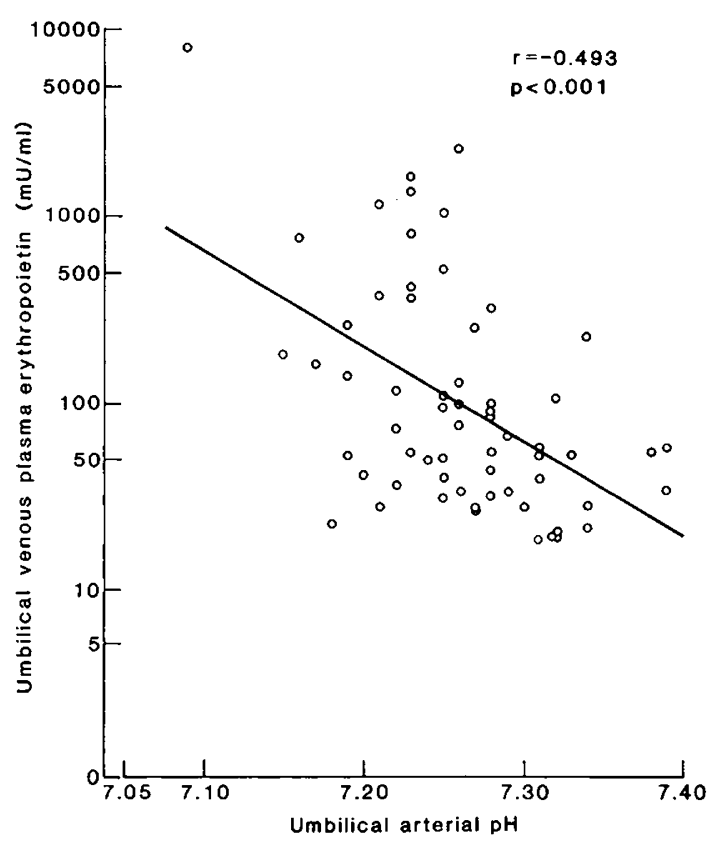

Fig. 2. Correlation between logarithmically transformed umbilical venous plasma $\mathrm{EP}$ concentration and umbilical arterial $\mathrm{pH}$ in the infants born after severe preeclampsia $(n=62)$. The regression line $(Y=89.43$ $-11.68 \times \mathrm{X})$ is shown. 
In the acute asphyxia group, umbilical arterial $\mathrm{HX}$ concentrations were significantly $(p=0.001)$ higher than in the control group (Table 2). The levels were correlated with $\mathrm{pH}(r=-0.647$, $p<0.001$, Fig. 3), lactate $(r=0.558, p=0.008)$, and AVP $(r=$ $0.588, p=0.005$, Fig. 4 ), but not with the Apgar score, or EP.

Hypoxia parameters in relation to neonatal morbidity. In the preeclampsia group, the number of infants with significant neonatal problems was too small for assessing their relationship to the hypoxia parameters.

In the asphyxia group, only the need of mechanical ventilation was associated with higher AVP $(p=0.011)$ and $\mathrm{HX}(p=0.015)$ concentrations than in asphyxiated infants with spontaneous respiration, whereas no difference was found in EP or lactate concentrations, or in $\mathrm{pH}$.

In discriminant analysis, the positive predictive value of the combination of the 5-min Apgar score with umbilical arterial $\mathrm{pH}$ with respect to hypoxic-ischemic encephalopathy (16) was $80 \%$ and the negative value was $92 \%$. The concentrations of AVP, EP, and HX were entered into the analysis separately, inasmuch as the number of infants with data on all three parameters was too small. However, none of these variables improved

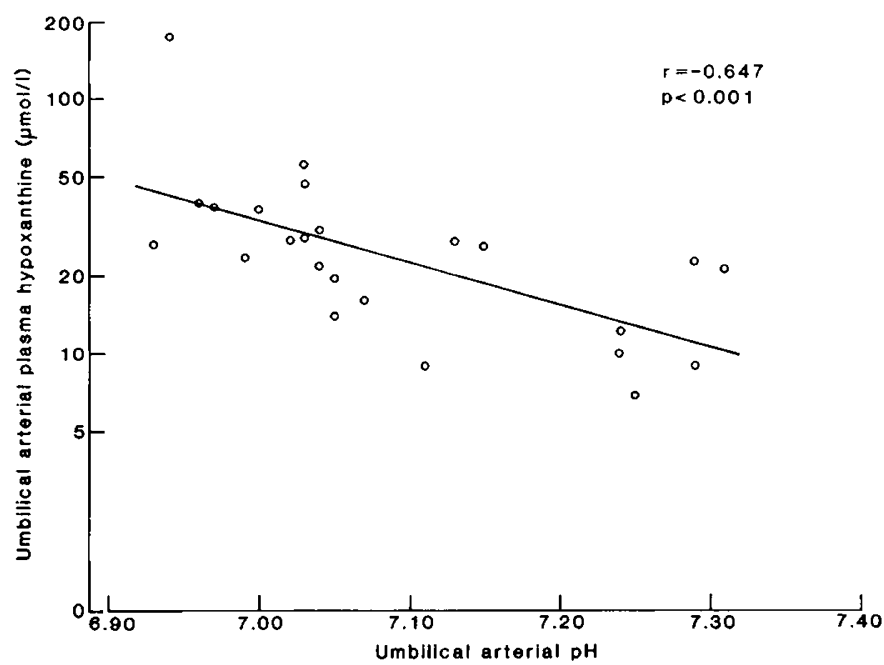

Fig. 3. Correlation between logarithmically transformed plasma hypoxanthine concentration and $\mathrm{pH}$ in umbilical artery of acutely asphyxiated infants $(n=24)$. The regression line $(\mathrm{Y}=30.04-3.79 \times \mathrm{X})$ is shown.

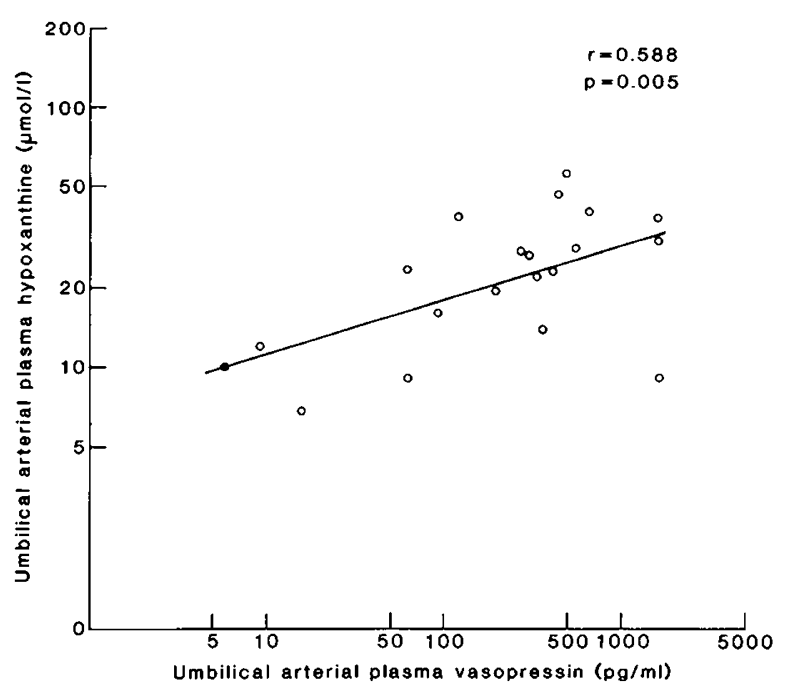

Fig. 4. Correlation between umbilical arterial hypoxanthine and vasopressin in acutely asphyxiated infants $(n=20)$. The regression line $(\mathrm{Y}=1.93+0.21 \times \mathrm{X})$ is shown. Note the logarithmic transformations. the positive or negative predictive value of the Apgar score and $\mathrm{pH}$.

\section{DISCUSSION}

Perinatal asphyxia is an important clinical problem because of its potential for causing permanent damage, even death, of the fetus or newborn infant (17). The value of any biochemical parameter for defining or diagnosing asphyxia thus depends on if it reflects the basic pathophysiology. The problem is that there is no "gold standard" for defining the condition and for comparing other potential indicators. For this reason, the sensitivity and specificity of such indicators cannot be estimated.

Tissue hypoxia, hypercarbia, and ischemia are the basic components of asphyxia, and they all contribute to the progressive metabolic derangement of the cell, ending up in cell death. However, because of physiologic protective mechanisms, including redistribution of blood flow (4), the organs of the body are affected to a different extent. Therefore, although the accumulation of products of anaerobic metabolism indicate that some organ(s) of the body have been subjected to hypoxia, no conclusions can be drawn about the state of the vital organs, e.g. the central nervous system.

In experimental acute total asphyxia, the rapid development of combined metabolic and respiratory acidosis is closely associated with bradycardia and flattening of the EEG, suggesting that the newborn animal would certainly have a low Apgar score (18). In the clinical situation, we and others have shown that the Apgar score is poorly correlated with metabolic acidosis, measured in umbilical arterial blood $(2,15)$. Low score with normal $\mathrm{pH}$ may be explained by CNS depression due to causes other than asphyxia, e.g. maternal medication or infant immaturity (19). Normal score with low $\mathrm{pH}$ may be due to cellular hypoxia and lactate production in tissues other than the CNS.

In the present study, none of the measured variables was correlated with the Apgar score, but AVP and HX did correlate with arterial $\mathrm{pH}$ and lactate in the acutely asphyxiated infants. Thus, they may reflect the same basic abnormality. Hypoxia is a known trigger of AVP secretion in the fetal lamb (20), but other stimuli have been identified, e.g. hypovolemia (21). The mode of delivery influences markedly AVP secretion (5). Elevated levels have been demonstrated in asphyxiated infants in cord blood and during the first 2 days of life $(22,23)$.

When cellular oxygen supply is compromised, ATP is partly catabolized to $\mathrm{HX}$, and elevated concentrations have been found after experimental (24) and clinical perinatal asphyxia $(9,25-$ 27). However, the relationship between plasma $H X$ and tissue hypoxia is not straight forward (28-31). Inasmuch as metabolic acidosis due to lactate release is also associated with tissue hypoxia, this is the likely common trigger and accounts for the correlation between these parameters in the present study. Asphyxiated infants requiring mechanical ventilation had higher AVP and HX levels than those without depression of respiration, whereas infants with hypoxic-ischemic encephalopathy had similar AVP and HX levels as those not developing this complication. Thus, umbilical arterial AVP and HX can be considered as a measure of hypoxia before birth, but they give no information on the severity of postasphyxial morbidity.

Cord plasma EP concentrations were not consistently elevated in acutely asphyxiated infants, and no differences were found between severely ill infants and those recovering quickly. This may be due to the time factor, because in animal experiments acute fetal hypoxia is followed by increased plasma EP levels after a delay of approximately $4 \mathrm{~h} \mathrm{(8)}$. Our finding of higher concentrations after vaginal delivery than after elective cesarean section in the control group, as in a previous study (32), is in agreement with delayed release and also suggests that even in supposedly normal vaginal delivery the fetus is subjected to some degree of hypoxia. No other triggers for EP secretion are known. The severity of hypoxia in acutely asphyxiated infants could 
perhaps be assessed by EP if plasma levels in the newborn infant some hours after birth could be measured in addition to cord level.

The infants of mothers with preeclampsia were mostly born in good condition, although many were preterm and small for gestational age. This is probably due to careful monitoring and early elective delivery. HX concentrations were normal regardless of mode of delivery, as were AVP levels in those infants delivered by cesarean section. The most prominent abnormality was the high mean EP concentration, particularly in those delivered by elective cesarean section. These mothers usually had more severe preeclampsia, which may account for the higher EP levels than in vaginally delivered infants. Maternal preeclampsia appears to be frequently associated with latent or mild fetal hypoxia, sufficient to trigger an EP response but no change in the other biochemical indicators of asphyxia was seen except for $\mathrm{pH}$ which was slightly lower than in controls. Recent studies on fetal aortic blood flow in preeclampsia suggest that the supply of oxygenated blood to abdominal organs - may be compromised (33). This would include the liver, which is the known "sensor" organ for EP response and the site of fetal EP synthesis (34).

Although cord plasma AVP and HX seem to reflect acute and EP chronic asphyxia, their use for defining or grading asphyxia for research or clinical purposes may be limited. Asphyxia is the most likely mechanism responsible for the AVP secretion during parturition (5). In fetal sheep (35), metabolic acidosis produces only a 2-fold and hypoxemia a 4-fold rise of AVP release, compared to about 200 -fold increase in response to a combination of hypoxemia, metabolic acidosis, and hypercapnia (i.e. asphyxia). HX, as with lactate, may be released by any organ and, unlike AVP and EP, cleared by the placenta by metabolism or transport into the mother (29). The time course for the onset and cessation of EP release has not been studied in the human infant. The ultimate value of these parameters will depend on if they reflect the risk of brain damage due to asphyxia any better than our current indicators.

\section{REFERENCES}

1. Apgar A, James LS 1962 Further observations on the newborn scoring system. Am J Dis Child 104:419-428

2. Sykes GS, Molloy PM, Johnson P, Gu W, Ashworth F, Stirrat GM, Turnbull AC 1982 Do Apgar scores indicate asphyxia? Lancet 1:494-496

3. Nelson KB, Ellenberg JH 1981 Apgar scores as predictors of chronic neurologic disability. Pediatrics 68:36-44

4. Rudolph AM, Itskovitz J, Iwamoto H, Reuss ML, Heymann MA 1981 Fetal cardiovascular responses to stress. Semin Perinatol 5:109-121

5. DeVane GW, Porter JC 1980 An apparent stress-induced release of arginine vasopressin by human neonates. J Clin Endocrinol Metab 51:1412-1416

6. Bacigalupo G, Langner K, Schmidt S, Saling E 1987 Plasma immunoreactive beta-endorphin, ACTH and cortisol concentrations in mothers and their neonates immediately after delivery-their relationship to the duration of labor. J Perinat Med 15:45-52

7. Finne PH 1966 Erythropoietin levels in cord blood as an indicator of intrauterine hypoxia. Acta Paediatr Scand 55:478-489

8. Widness JA, Teramo KA, Clemons GK, Garcia JF, Cavalieri RL, Piasecki GJ, Jackson BT, Susa JB, Schwartz R 1986 Temporal response of immunoreactive erythropoietin to acute hypoxemia in fetal sheep. Pediatr Res 20:15-19

9. Saugstad OD 1988 Hypoxanthine as an indicator of hypoxia: its role in health and disease through free radial production. Pediatr Res 23:143-150
10. Teramo KA, Widness JA, Clemons GK, Voutilainen P, McKinlay S, Schwartz R 1987 Amniotic fluid erythropoietin correlates with umbilical plasma erythropoietin in normal and abnormal pregnancy. Obstet Gynecol 69:710715

11. Pohjavuori M, Raivio KO 1985 The effects of acute and chronic perinatal stress on plasma vasopressin concentration and renin activity at birth. Biol Neonate 47:259-264

12. Simmonds RJ, Harkness RA 1981 High-performance liquid chromatographic methods for base and nucleoside analysis in extracellular fluids and in cells. J Chromatogr 226:369-381

13. Fyhrquist F, Wallenius M, Hollemans HJ 1976 Radioimmunoassay of vasopressin in unextracted plasma. Scand J Lab Clin Invest 36:841-847

14. Garcia JF, Ebbe SN, Hollander L, Cutting HO, Miller ME, Cronkite EP 1982 Radioimmunoassay of erythropoietin: circulating levels in normal and polycythemic human beings. J Lab Clin Med 99:624-635

15. Ruth VJ, Raivio KO 1988 Perinatal brain damage: predictive value of metabolic acidosis and Apgar score. Br Med J 297:24-27

16. Fenichel GM 1983 Hypoxic-ischemic encephalopathy in the newborn. Arch Neurol 40:261-266

17. Hill A, Volpe JJ 1982 Hypoxic-ischemic brain injury in the newborn. Semin Perinatol 6:25-41

18. Vannucci RC, Duffy TE 1977 Cerebral metabolism in newborn dogs during reversible asphyxia. Ann Neurol 1:528-534

19. Goldenberg RL, Huddles JF, Nelson KG 1984 Apgar scores and umbilical arterial pH in preterm newborn infants. Am J Obstet Gynecol 149:651-654

20. Daniel SS, Stark RI, Husain MK, Sanocka UM, James LS 1984 Excretion of vasopressin in the hypoxic lamb: comparison between fetus and newborn. Pediatr Res 18:227-231

21. Alexander DP, Britton HG, Forsling ML, Nixon DA, Ratcliffe JG 1974 Pituitary and plasma concentrations of adrenocorticotrophin, growth hormone, vasopressin and oxytocin in fetal and maternal sheep during the latter half of gestation and the response to haemorrhage. Biol Neonate 24:206219

22. Polin RA, Husain MK, James LS, Frantz AG 1977 High vasopressin concentrations in human umbilical cord blood-lack of correlation with stress. J Perinat Med 5:114-119

23. Speer ME, Gorman WA, Kaplan SL, Rudolph AJ 1984 Elevation of plasma concentrations of arginine vasopressin following perinatal asphyxia. Acta Paediatr Scand 73:610-614

24. Thiringer K, Saugstad OD, Kjellmer I 1980 Plasma hypoxanthine in exteriorized, acutely asphyxiated fetal lambs. Pediatr Res 14:905-909

25. Saugstad OD, Gluck L 1982 Plasma hypoxanthine levels in newborn infants: a specific indicator of hypoxia. J Perinat Med 10:266-272

26. Thiringer K 1983 Cord plasma hypoxanthine as a measure of foetal asphyxia. Acta Paediatr Scand 72:231-237

27. Swanström S, Bratteby L-E 1982 Hypoxanthine as a test of perinatal hypoxia as compared to lactate, base deficit, and $\mathrm{pH}$. Pediatr Res 16:156-160

28. Lipp-Zwahlen AE, Tuchschmid P, Silberschmidt M, Duc G 1983 Arterial cord blood hypoxanthine: a measure of intrauterine hypoxia? Biol Neonate 44:193-202

29. Tuchschmid PE, Boutellier U, Koller EA, Duc GV 1981 Comparison of hypoxanthine, lactate, and ECG signs as indicators of hypoxia. Pediatr Res 15:28-33

30. Ruth V, Raivio KO 1984 Purine metabolites and lactate as parameters of hypoxia in the newborn infant. Pediatr Res 18:355-358

31. Jung D, Lun A, Zinsmeyer J, Grauel EL, Gross J 1985 The concentration of hypoxanthine and lactate in the blood of healthy and hypoxic newborns. $J$ Perinat Med 133:43-50

32. Widness JA, Clemons GK, Garcia JF, Oh W, Schwartz R 1984 Increased immunoreactive erythropoietin in cord serum after labor. Am J Obstet Gynecol 148:194-197

33. Hackett GA, Campbell S, Gamsu H, Cohen-Overbreek T, Pearce JMF 1987 Doppler studies in the growth retarded fetus and prediction of neonatal necrotising enterocolitis, haemorrhage, and neonatal morbidity. $\mathrm{Br}$ Med $\mathrm{J}$ 294:13-16

34. Sherwood JB 1984 The chemistry and physiology of erythropoietin. Vitam Horm 41:161-211

35. Faucher DJ, Lowe TW, Magness RR, Laptook AR, Porter JC, Rosenfeld CR 1987 Vasopressin and catecholamine secretion during metabolic acidemia in the ovine fetus. Pediatr Res 21:38-43 